\title{
A scientific career launched at the start of the space age: Michael Rycroft at 80
}

\author{
Karen L. Aplin ${ }^{1}$, R. Giles Harrison ${ }^{2}$, Martin Füllekrug ${ }^{3}$, Betty Lanchester ${ }^{4}$, and François Becker ${ }^{5}$ \\ ${ }^{1}$ Department of Aerospace Engineering, University of Bristol, University Walk, Bristol BS8 1TR, UK \\ ${ }^{2}$ Department of Meteorology, University of Reading, P.O. Box 243 Reading RG6 6BB, UK \\ ${ }^{3}$ Department of Electronic and Electrical Engineering, University of Bath, Claverton Down, Bath BA2 7AY, UK \\ ${ }^{4}$ Department of Physics and Astronomy, University of Southampton, \\ University Road, Southampton, SO17 1BJ, UK \\ ${ }^{5}$ International Space University, 1 rue Jean-Dominique Cassini, \\ Parc d'Innovation, 67400 Ilkirch-Graffenstaden, France \\ Correspondence: Karen L. Aplin (karen.aplin@bristol.ac.uk)
}

Received: 9 February 2020 - Accepted: 29 April 2020 - Published: 29 May 2020

\begin{abstract}
The scientific career of Michael Rycroft (born in 1938) spans the space age, during which significant changes have occurred in how scientists work, experiment, and interact. Here, as part of his 80th birthday celebrations, we review his career to date in terms of the social and structural changes in collaborative international science. His contributions to research, teaching, and management across solar-terrestrial and ionospheric physics as well as atmospheric and space science are also discussed.
\end{abstract}

\section{Introduction}

The 20th century saw the nature of a career in scientific research change profoundly. In its second half, the physical sciences moved towards a more collaborative model with less emphasis on the individual, through more team working and the use of large shared facilities. In particle physics, the post-war development of the European Organization for $\mathrm{Nu}$ clear Research (CERN) particularly exemplifies this shared and distributed model of working. In atmospheric science, institutions such as the Met Office and the British Antarctic Survey as well as some university departments provided infrastructure to link measurement, modelling, and analysis. In space science, a combination of university departments and national or international entities, such as the European Space Agency (ESA) and the National Aeronautics and Space Administration (NASA), underpinned the development of satellite technology and planetary missions. As these developments occurred, the role and expectations of the scientist also changed, and careers began to evolve due to the careful choices of the individual concerned. This is contrast to a scientist working as a solitary investigator and largely ac- cepting the directions and opportunities provided by a single institution throughout a working life.

In preparing a celebratory symposium for Professor Michael John Rycroft's 80th birthday held in Bath in November 2018, it became clear that his career had spanned many of these significant changes in scientific activity. The perspective that Rycroft's career brings to understanding the late 20th century and early 21 st century scientist may therefore have wider value; hence, the discussions and presentations from his birthday symposium have been further distilled here by some of the original contributors. In doing this, it is hoped to provide some insight into the basis for choices which are now commonly made by scientists at key points in their working life, whilst also providing a summary of the successful career of a generous and widely respected individual who remains very active as a researcher in the space and atmospheric sciences.

\section{Education - scientific training at Cambridge}

Following a first degree in physics at Imperial College London, Michael Rycroft was amongst the first cohort of post- 
graduate students to arrive at the newly founded Churchill College in Cambridge in 1960. He was registered with the university for a $\mathrm{PhD}$ in the Meteorological Physics Group at the Cavendish Laboratory under the supervision of Dr. Thomas W. (Will) Wormell.

\subsection{Meteorological physics at Cambridge before 1960}

Atmospheric physics, or meteorological physics as the research group was named, at Cambridge, had a long and distinguished history, mainly due to the influence of Charles Thomas Rees Wilson (who was always known as "CTR"). CTR's career was dominated by a fascination with atmospheric science and, in particular, atmospheric electricity, which had been triggered by a 2-week stay at Ben Nevis Observatory in 1894 . The cloud chamber, which earned CTR the 1927 Nobel Prize, was an attempt to recreate phenomena he had seen on Ben Nevis. Despite the significance of the cloud chamber for particle physics and the huge research effort it triggered at Cambridge and elsewhere, CTR worked exclusively on atmospheric electricity for the rest of his long life, between Cambridge's Cavendish Laboratory and its Solar Physics Observatory located west of the town centre on Madingley Road (Harrison, 2011). Even by the standards of the time, CTR had relatively few co-workers, due to his "shy and very modest" personality (Dee and Wormell, 1963). Philip Dee, one of his few postgraduate students, even suggested that CTR had moved to the observatory: "nominally, he always claimed, to get away from the radioactive contamination in the Cavendish, but I suspect in order to live in a quieter atmosphere" (Dee, 1971). This meant that CTR's research programme developed relatively slowly at Cambridge. An Indian student, Prasanta Chandra Malhanobis, was recruited before the onset of World War I but was in India when war broke out and never returned. CTR's next PhD student was Wormell, taken on about the same time as Cecil Powell in 1925; Wormell "started on some experiments on thunderstorms in which Wilson had been interested for many years..." (Powell, undated; reproduced in 1987), obtaining his $\mathrm{PhD}$ on the electrical properties of rain in 1929 (Wormell, 1929). (A student contemporary of Wormell at Cambridge, John Alan Chalmers, began similar experiments at Durham after his own $\mathrm{PhD}$, establishing a strong and enduring base for atmospheric electricity in the North of England (Aplin, 2018).)

Wormell worked at the Solar Physics Observatory for many years and developed broad interests in atmospheric physics, before becoming university lecturer in meteorological physics at the Cavendish Laboratory in 1950 (Longair, 2016). It was this research group, at that time with around six members, that Michael Rycroft joined in 1960. Rycroft's colleagues included Desmond Walshaw, a senior researcher in atmospheric infrared absorption, who supervised students Clive Rodgers and David Wardle (Clive Rodgers, personal communication, 2019; Longair, 2016), and another PhD stu- dent, John Law, who was working on atmospheric electricity in the boundary layer. In addition, there was active collaboration on radio work with Kenneth Budden and Phillip C. Clemmow and their students after the departure of John A. Ratcliffe (out of whose group the famous radio astronomy activity at Cambridge under Martin Ryle ultimately grew) (Longair, 2016) to the Department of Scientific and Industrial Research (DSIR) Radio and Space Research Station at Slough.

\subsection{Measuring the Schumann resonances}

Michael Rycroft joined the Cavendish Laboratory at a time when the old "sealing wax and string" tradition was very much in evidence ${ }^{1}$ but also when technologies such as the digital computer and early satellite experiments were rapidly developing. This combination of experimental and computational work is fully reflected in his thesis, entitled "Low frequency disturbances of natural origin of the electric and magnetic field of the earth" (Rycroft, 1964).

The background to this research project was the theoretical prediction by Otto Schumann that the Earth and the top of the atmosphere could act as a waveguide for low-frequency radio waves produced by thunderstorms (Schumann, 1952). Schumann's student Herbert König aimed to confirm the theoretical prediction of his mentor (e.g. Schumann and König, 1954), but his results were not accepted by the establishment as reliable detections, possibly as a result of the narrowband character of the experimental capability available at the time, similar to Polk and Fitchen's (1962) early measurements. So it was left to Balser and Wagner (1960) to become the first to detect Earth-ionosphere cavity resonances reliably, with their results quickly confirmed by numerous groups (Fournier, 1960; Lokken et al., 1961; Benoit and Houri, 1961; Jones, 1963; Rycroft, 1964) and discussed during the seventh meeting of the Advisory Group for Aerospace Research and Development (AGARD) Ionospheric Research Committee in Munich in 1962 (Blackband, 1964).

Ultimately, Rycroft detected the Schumann resonances using a valve-based extremely low-frequency (ELF) receiver, from which signals were self-recorded by filming the trace on a cathode ray oscilloscope, and using a device made from Meccano and deploying a clock motor, a gramophone motor, and a car headlight bulb to digitise this waveform onto punched paper tape (Rycroft, 1964; Rycroft and Wormell, 1964). The measurements were taken close to a hut known as "Wilson's hut" (Fig. 1) located off Madingley Road, west of Cambridge:

\footnotetext{
${ }^{1}$ Sealing wax was actually used in the Cavendish meteorological physics group to ensure waterproofing when flying photographic plates on weather balloons to search for high-energy particles produced by or accelerated in thunderclouds (Macky, 1933). This had been one of CTR Wilson's many forward-thinking ideas in atmospheric electricity.
} 


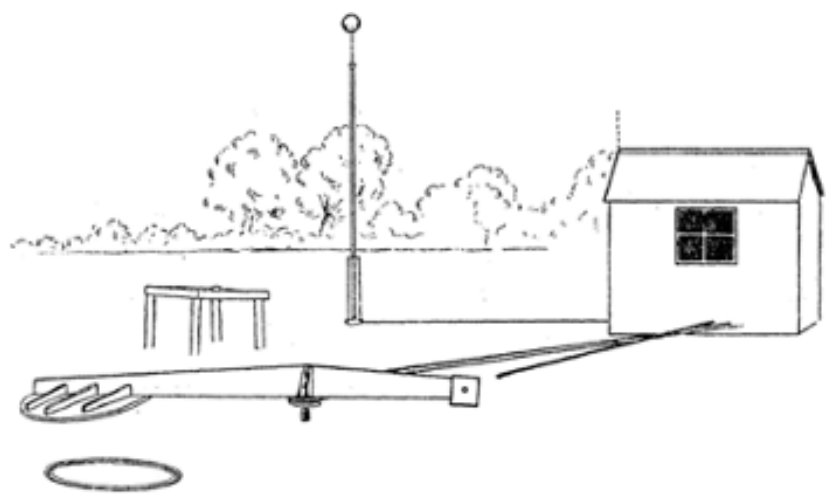

Figure 1. Wilson's early hut (reproduced with permission from Wilson, 1916).

Wilson's green painted hut was in the middle of an open field when I did my $\mathrm{PhD}$, using as an aerial the telephone line connected to the said hut. Nowadays that is where the Cavendish lab is. (Michael J. Rycroft, personal communication, 2016)

Considerable effort was required to identify and remove anthropogenic signals such as the power grid at $50 \mathrm{~Hz}$ and Morse code transmitted by the Rugby long-wave radio station (GBR) at $16 \mathrm{kHz}$ as well as natural signals of local origin such as those generated by the wind-excited oscillations of the aerial in the local atmospheric electric field (Rycroft, 1964). The autocovariance function and the power spectral density of the ELF signal were computed (SwinnertonDyer, 1963) from the digitised signals using Cambridge's EDSAC 2 computer to identify the characteristic Schumann resonance signals at 8,14 , and 20 counts per second (c/s; now termed $\mathrm{Hz}$ ). What we might now call "space weather events" were also detected in the form of "hiss" and "chorus" for the sudden commencement of a magnetic storm on 27 September 1963. His thesis demonstrates that Rycroft was always ready to exploit the available modern technology whilst remaining fully grounded in the strong and rigorous Cavendish Laboratory scientific tradition. This approach continued throughout his career.

Rycroft attended a course on "Geophysics: the Earth's Environment" at the Les Houches Summer School of Theoretical Physics in 1962. Here he met John R. Spreiter of the NASA Ames Research Center in California. This led to Rycroft joining Spreiter's group there as a NAS/NRC postdoctoral research associate early in 1964. His impressions of this time are outlined in Rycroft (2020). He then spent the 1965-1966 academic year in the space research group of James W. Dungey at Imperial College London. Much of his research there was on the plasmapause and on Alouette I observations of the topside ionosphere, carried out in collaboration with John O. Thomas.

\section{University of Southampton (1966-1979)}

Rycroft was appointed lecturer at the University of Southampton in 1966. During the next 13 years he had a continuous line of students and postdoctoral researchers who were important experimental collaborators in his research using ELF ( $3 \mathrm{~Hz}$ to $3 \mathrm{kHz}$ ) and VLF (very low frequency; 3 to $30 \mathrm{kHz}$ ) radio waves. In Fig. 2, the metal structure visible behind the group is Rycroft's VLF aerial before it was put on the roof. He established a VLF receiver on the island of South Uist in the Outer Hebrides. There, he observed a burst of X-rays on a rocket launched from the island, due to precipitating electrons from the magnetosphere coincident in time with a half-hop whistler; he interpreted this as being due to a cyclotron resonance interaction between whistler-mode waves and energetic electrons at the geomagnetic equator (Rycroft, 1973). In collaboration with Tom R. Kaiser's group at Sheffield University, his group also conducted Petrel and Skylark rocket launches from the Hebrides and from Kiruna, Sweden, to observe the strength and polarisation of naturally occurring VLF radio signals in the lower ionosphere.

Fieldwork was an important aspect of Rycroft's approach at this time, taking him to many places (Fig. 3). He carried out ground-based observations of VLF signals and whistlermode emissions in Iceland in 1969 with a group of six recent graduates (Reeve and Rycroft, 1971) as well as with graduate students at Troms $\varnothing$ (Norway), Kiruna (Sweden), and Sodankylä (Finland). From time to time, Turunen et al. (1980) heard snatches of the tune Midnight in Moscow being broadcast from the lower ionosphere; this was explained as being due to non-linear phenomena there induced by powerful radio transmitters across the Soviet Union just before the hour UT (universal time). His group made VLF observations using direction-finding (goniometer) receivers in Newfoundland during the solar eclipse of 7 March 1970 (Reeve and Rycroft, 1972) and in eastern Canada in association with the total solar eclipse of 10 July 1972. Such observations were also made in Alaska when a barium release from a large rocket injected ions into the magnetosphere. He had a sabbatical, as a visiting professor at the University of Houston for the 1974-1975 academic year, whilst W. Robert (Bob) Sheldon was pursuing research on Kerguelen Island.

Those who worked with Rycroft have described their time at Southampton as being strongly and positively influenced by him. His infectious enthusiasm was a key attribute that gave his Space Radiophysics Group a "can-do" attitude, even when there were difficulties. All agreed that a huge benefit to their careers was the fact that Michael encouraged them to take responsibility at a very early stage. He also went out of his way to introduce his students to the relevant contacts at conferences, and, as his publication list proves, he made sure that they had due credit in the authorship of papers. With colleagues in the geology and oceanography departments as well as in physics, Rycroft was instrumental in setting up a 


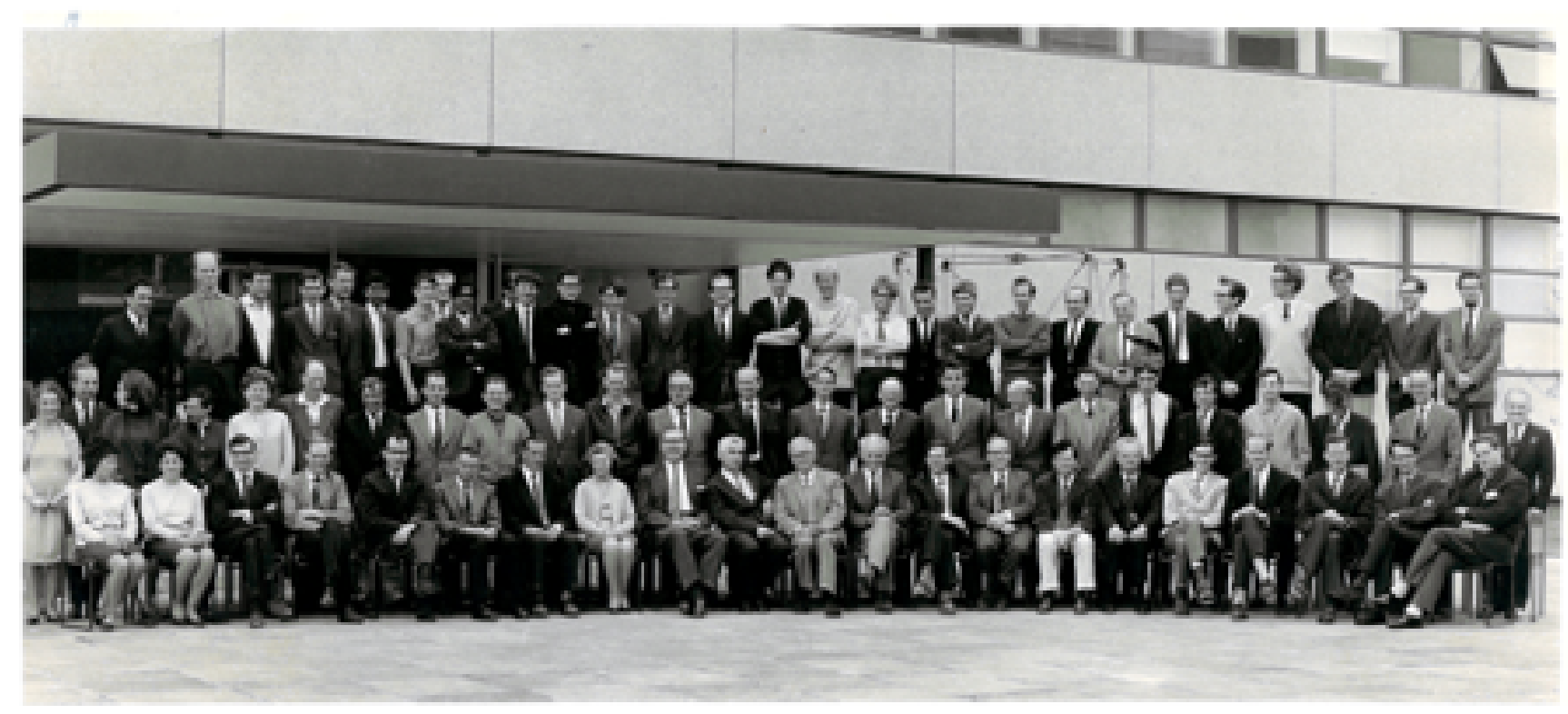

Figure 2. Southampton University Physics Department, circa 1967. Rycroft is seated in the front row, fourth from the right. Reproduced with permission of the current head of department, Prof. Mark Sullivan.

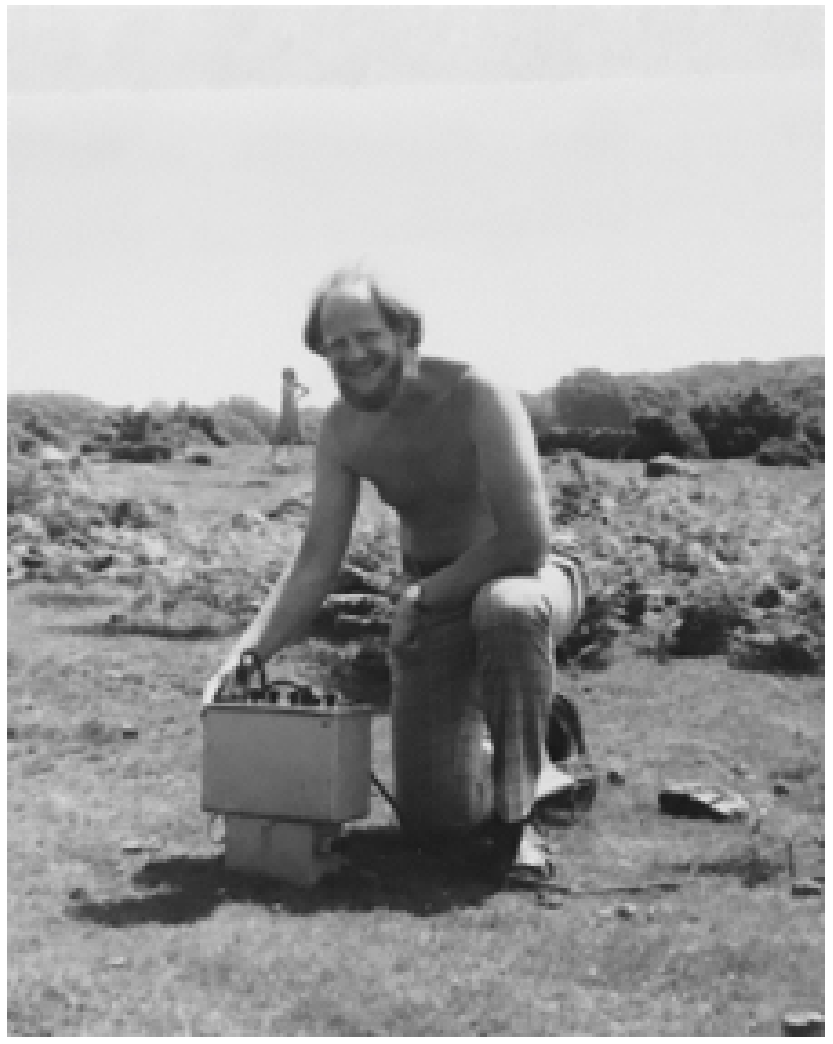

Figure 3. Michael Rycroft checking a magnetometer on a field trip in Devon, on a hot day in July 1977. Photo provided by Prof. Mark Saunders. geophysical sciences degree at Southampton, which is still successfully recruiting undergraduate students.

During his time at Southampton, Rycroft was shortlisted to become one of the five British candidates for the position of payload specialist (scientist-astronaut) aboard the first Spacelab flight in 1977. Although this adventure was not to be, it acted as an inspiration for Mark Saunders, who had been one of the early cohort of students in Southampton's geophysical sciences degree as well as Rycroft's tutee and a final year project student with him. Saunders chose to do a $\mathrm{PhD}$ in space physics and subsequently applied to become the first British astronaut in 1989, when Helen Sharman was selected. He sums up the qualities that encapsulate Rycroft's time at Southampton; they are echoed by all of his ex-students who were contacted for the preparation of this article. All agreed that he was an inspiration to young scientists, a great organiser and enabler, as well as a gentleman and a diplomat.

The evolution of Rycroft's research is mirrored in the fastchanging technology including space exploration that was burgeoning in the first decades of the "space age". During the 1970s and 1980s, Rycroft began a continuous string of publications in "News and Views" in Nature (e.g. Rycroft, 1977, 1982). These perhaps followed naturally from his wellknown ability at Southampton (and subsequently) to make copious notes summarising every research presentation and then ask an insightful question. These articles make enjoyable reading and remain instructive today; they are wide ranging, informative, and perceptive about the future of the field. Further, during the 1970s, he was an editor of the annual COSPAR (Committee on Space Research) volume on 
space research results from around the world and a member of the Science Research Council Solar System Committee.

\section{British Antarctic Survey (1979-1990)}

Rycroft left Southampton to become head of the Atmospheric Sciences Division at the British Antarctic Survey (BAS) in Cambridge in 1979; following the expansion of BAS after the Falklands conflict, he was appointed head of the Upper Atmospheric Sciences Division in 1987. There, groups made observations of the neutral atmosphere and studied the plasma environment above. Rycroft is reported to have brought more emphasis and breadth of research, a wider perspective, and a collaborative approach, seeing his responsibility as a senior scientist to ensure the institution's reputation was enhanced by good research. For example, a report from the Neutral Atmosphere Advisory Panel in 1984 welcomed his "aim to continue the change from a largely observational approach to a more experimental and analytical approach..." (Richard Horne, personal communication, 2018). He encouraged publication in the BAS annual report of the observed warming trend in the Antarctic Peninsula. Rycroft recognised the immense significance of the ozone hole's discovery by BAS scientists and sought to ensure it was correct before publication (Farman et al., 1985; Farman, 2010). Rycroft then championed the work, playing a full role in publicising the ozone hole (e.g. he delivered invited lectures to the Royal Geographical Society and to the Scientific Committee on Antarctic Research, SCAR, general assemblies) and other findings from his colleagues, particularly through SCAR and his Nature "News and Views" pieces (discussed in Sect. 3). He was elected a member of the International Academy of Astronautics in 1985. He also encouraged participation in the NASA Global Geospace Science mission entitled Origin of Plasmas in the Earth's Neighbourhood (OPEN), with the OPEN SESAME (Satellite Experiments Simultaneous with Antarctic Measurements) proposal. Despite Rycroft's ability to come up with acronyms for many projects, his late colleague Dyfrig Jones thought up that acronym. With David Shapland, he wrote "Spacelab: Research in Earth Orbit", published by Cambridge University Press (CUP) in 1984. He organised an international conference in Cambridge in 1986 on Atmospheric Studies by Optical Methods and another, in 1988, on Auroral Physics. From 1988 to 1990 he was an editor of the journal Antarctic Science.

Rycroft's first visit to Antarctica was in 1981, and he visited several bases run by the UK, USA, Argentina, and Poland. He comments on the USA's Palmer station were that it was a "huge base with many empty labs, think what BAS could do with the facilities there". He was less complementary about the UK's stations, advising for Halley that "Better hot water system needed so that showers can be had more often than weekly" and for Faraday that "Excessive quantity of alcohol consumed; drinking started before $11 \mathrm{am}$ " (Richard Horne, personal communication, 2018). It is not known whether this note originated as a personal memo.

During Rycroft's time at BAS, the Falklands conflict led to the development of upper atmosphere research, including six new appointments in 1983-1984 of which two were permanent. Under Rycroft's leadership there were many scientific developments, new links with UK universities, international collaborations, and a huge increase in the number of publications. Valuable work was conducted on planetary radio emissions, very low-frequency radio waves, and magnetospheric wave-particle interactions. New projects and collaborations included new distributed geophysical observatories, the advanced ionospheric sounder, and the Halley Auroral Radar Experiment (HARE) project for ionospheric convection, which was the forerunner of the SuperDARN (Super Dual Auroral Radar Network) radar. He is remembered by colleagues as being always kind and encouraging, and with a genuine love for research, communication, and collaboration.

\section{Cranfield and the International Space University (1990s)}

Rycroft spent 4 years as professor of aerospace at Cranfield University; soon after he arrived there the Cambridge Encyclopedia of Space, which he edited, was published. He particularly encouraged the staff involved with the astronautics and space engineering MSc degree, and supervised the projects of several students; Paul Craven took a PhD degree under his supervision modelling the damage to DNA done by radiation in space. At this time he worked with David Nunn (Electronics Department of Southampton University), Viktor Trakhtengerts (Institute of Applied Sciences, Nizhny Novgorod, Russia), and Tauno Turunen and Jyrki Manninen (Sodankylä Geophysical University, Finland) to investigate, both experimentally and theoretically, triggered VLF radio emissions with INTAS and NATO financial support. Besides several papers on the generation mechanisms for ELF/VLF radio emissions and a CUP monograph with Trakhtengerts, this led to the popular VLF/ELF Remote Sensing of Ionospheres and Magnetospheres (VERSIM) meetings organised jointly by the International Union of Radio Science (URSI) and the International Association of Geomagnetism and Aeronomy (IAGA). He was an active editor for the Cambridge University Press series in atmospheric and space science, topics in remote sensing, and for aerospace.

In January 1995 he became full-time resident head of the School of Sciences and Applications at the new International Space University (ISU) Central Campus in Strasbourg, France. He worked with the head of the schools of management/social sciences and of engineering/technology, to design the detailed programme and the practical implementation and delivery of the "Master of Space Studies" 
(MSS) course, a brand new and original programme from the ISU. This was a true challenge, as this type of international, intercultural and interdisciplinary programme was totally new. The pedagogical challenge was also considerable, as the backgrounds of the attending students were extremely broad ranging from science, engineering, and computer sciences to economics, management, humanities, architecture, policy, and law. Rycroft delivered a paper at the 1996 COSPAR meeting held in Birmingham, UK, on the MSS programme. Together with Alice Houston, he edited the MSS core text entitled "Keys to Space"; with Giancarlo Genta, he wrote "Space: the Final Frontier?". He also edited several books arising from the annual symposium arranged for MSS students. The MSS programme started successfully and is still popular over 20 years later.

In addition to running the MSS course, Rycroft was appointed director of research, which involved organising the research at ISU; he was fortunate to have Mengu Cho as a teaching associate for the MSS course from 1995 to 1996, and they wrote a few research papers together. He also contributed to the delivery of other ISU programmes, such as the "Space Studies Programme" taught during the summer. Rycroft's own interdisciplinary and collaborative approach was well suited to space science, which came out clearly in his comments at that time:

The field of space science is vast, ranging from astronomy to zoology and encompassing my own interests in solar-terrestrial physics and atmospheric science. The number of space applications grows apace, with the areas of remote sensing of the Earth's environment and telecommunications being especially vigorous. By its very nature, space is a global subject, international and interdisciplinary in scope. I believe not only that this course is greatly needed, but also that its graduates will find rewarding and worthwhile careers... (Rycroft, 1995)

He was elected a member of Academia Europaea and awarded an honorary Doctorate of Science by De Montfort University in Leicester in 1998.

\section{6 "Retirement" and career summary}

\subsection{Key publications}

Rycroft's large body of publications can be regarded as having occurred in two major phases: the first, during the employed period of his career, concerning low-frequency radio waves in the atmosphere; and the second, following retirement, on the global atmospheric electric circuit (or "global circuit"). This is particularly evident from analysis of the titles of papers he co-authored, if the two phases are approximately regarded as being between 1960-1990 and 19912018 (Fig. 4).
The clear difference in the nature of these two phases of Rycroft's scientific publications can be seen by considering his annual publication rate and the rate at which his papers were cited by others (Fig. 5). Whilst some years were particularly productive, such as 2008 , the citation information indicates a significant change in the use of his work from about 2000. One paper which has been particularly well cited is the paper co-authored with Sven Israelsson and Colin Price on the global circuit in 2000 for the Golden Jubilee edition of the Journal of Atmospheric and Terrestrial Physics (now the Journal of Atmospheric and Solar-Terrestrial Physics, JASTP), for which Rycroft served as editor from 1989 to 1999.

The paper by Rycroft et al. (2000), entitled "The global atmospheric electric circuit, solar activity and climate change", did much to provide a modern and citable reference on the global circuit. Its success was probably helped by the fact that there were few up-to-date review articles on the topic available, and the classic atmospheric electricity textbooks of the 1960s and 1970s were becoming more difficult to obtain in the era before widespread internet access to library resources. In addition, the paper's strong conceptual diagram (Fig. 6) may well have played a significant role. The significance of Rycroft et al. (2000) can probably be linked to two important aspects: first, the paper firmly linked atmospheric electricity with solar activity, and secondly, with climate. It also included consideration of upper atmosphere discharges - sprites - which are still of interest today, but they were particularly fashionable at the time of publication.

The relationship between atmospheric electricity and solar studies had hitherto had a chequered history with work of variable quality, and solar-terrestrial links to the lower atmosphere were widely dismissed. Indeed, it is probably reasonable to say that the future of the whole topic of atmospheric electricity was then seen very differently between those working on the then separate fields of thunderstorms and "fair weather" atmospheric electricity, partly because of the solar aspects considered to be potentially damaging to the latter and, by implication, to the former. Rycroft et al. (2000) also firmly linked the ideas of atmospheric electricity with climate and the then emerging topic of climate change, which few prior studies had linked explicitly (an exception is Harrison, 1997). For this, the possible use of Schumann resonance (Williams, 1992) or the global circuit (Price, 1993) to provide information on global temperature offered ideas which were then developed by Rycroft et al. (2000) into regarding the global circuit as an integrated Earth system framework responding to climate change.

\subsection{Scientific networks}

An example of the sort of activity that became possible in the 1990s is the SPECIAL (Space Processes and Electrical Changes Influencing Atmospheric Layers) network. This was an European Science Foundation (ESF) scientific net- 

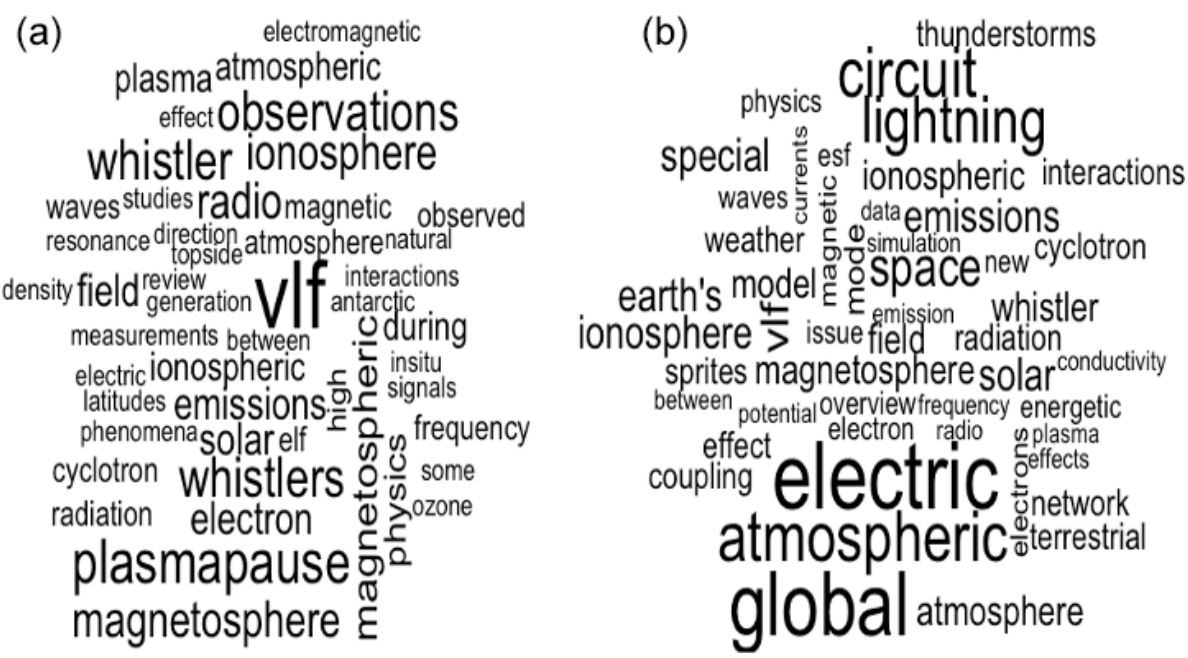

Figure 4. The most popular 50 words from Rycroft paper titles (a) 1964-1990 and (b) 1991-2018, printed at a size proportional to their rate of occurrence.

(a)

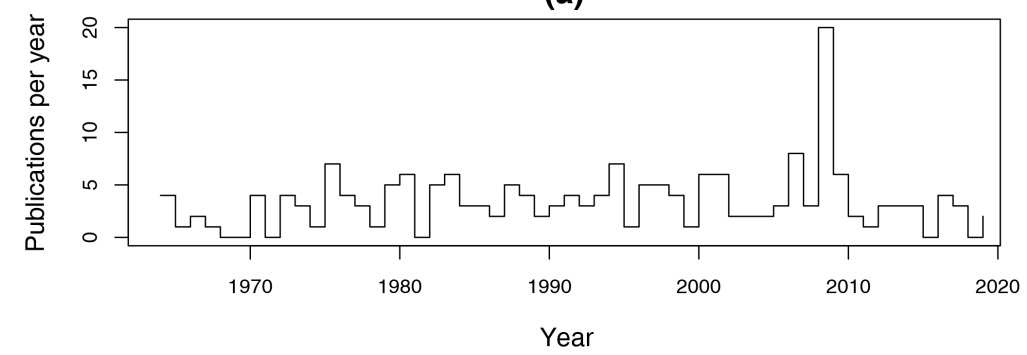

(b)

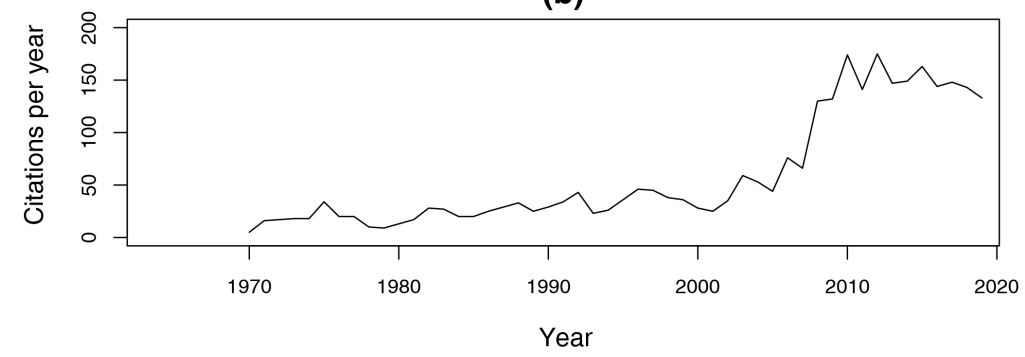

Figure 5. (a) Number of papers published annually, as author or co-author. (b) Annual number of citations of Rycroft's papers. Plots created in 2020 with data from Web of Science from 1970 to 2020; publications from 1964 to 1970 created manually from a list supplied by Michael Rycroft; citation data before 1970 are unavailable.

work which ran from 1999 to 2004 and has provoked several related training and other initiatives, some of which still continue. Its importance was that it highlighted the need to explore electrical linkages between different parts of the atmosphere, whilst recognising its holistic aspect (see Fig. 7). Rycroft was one of the proposers of SPECIAL.

In seeking to couple the space and ionospheric environments with the lower atmosphere, which was becoming ever more important because of the context provided by the emergence of climate science, SPECIAL provided a range of topics to which Rycroft was well positioned to contribute and make the crucial links between individuals required. Such scientific networks were and are largely self-organising in terms of the content and scope of meetings and the invitees chosen to contribute as well as in identifying and defining detail of the scientific questions they address. Nevertheless, it could be argued that they operate most effectively when there is a modest amount of constructive leadership, sufficiently enlightened that it is properly respected and supported by the members of the network but not so overbearing that it generates resentment. Rycroft was particularly well suited to making such networks successful, largely through 


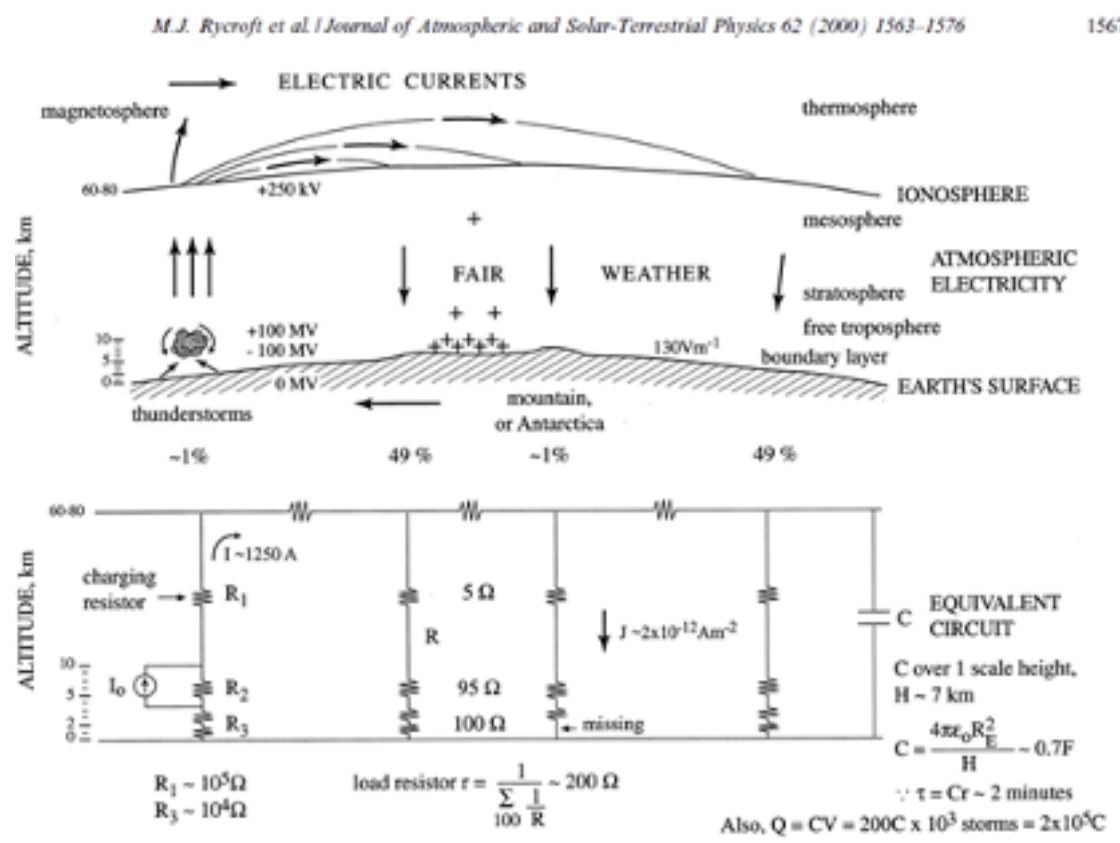

Figure 6. Global circuit concept diagram (from Rycroft et al., 2000).

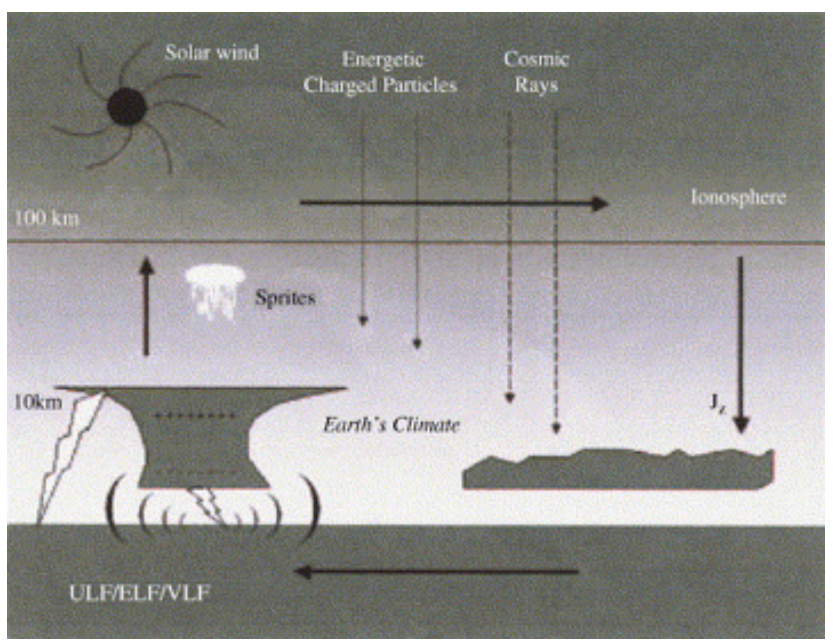

Figure 7. Concept diagram for topics in the SPECIAL network (from Rycroft and Füllekrug, 2004).

the catalysis provided by deep and extensive knowledge constructively offered with kindness, modesty, and warmth. His awareness of scientists working in related areas, obtained through his dedicated and long-standing journal editorships of the JASTP and then of Surveys in Geophysics, and through his founder membership of the European Geophysical Society (EGS; now the European Geophysical Union, EGU) and his role as general secretary of the EGS from 1996 to 2003, undoubtedly played a further role. Therefore, it is no surprise that his contribution to international scientific workshops and networks continues (Fig. 8).

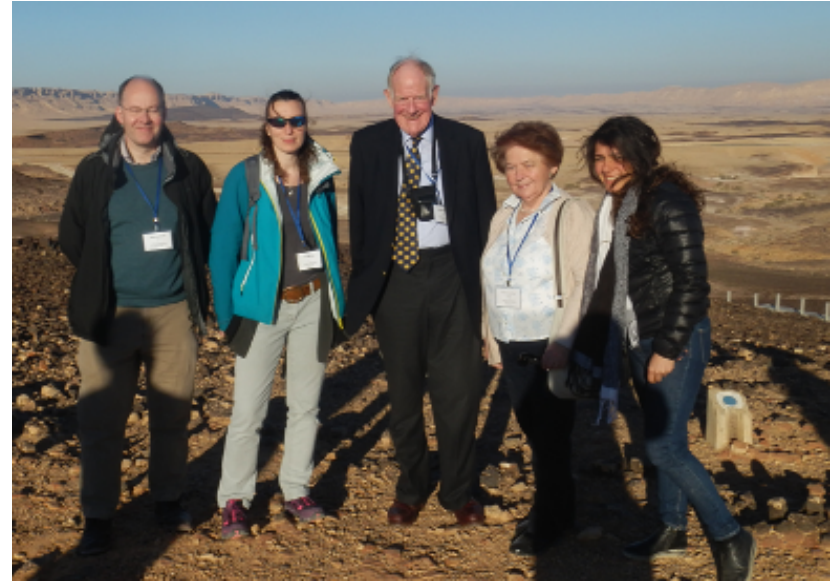

Figure 8. Discussing atmospheric electricity in the Negev Desert, February 2017, whilst attending the "Batsheva de Rothschild Workshop on the Atmospheric Global Electric Circuit" at Mitzpe Ramon. (Left to right: Giles Harrison, Keri Nicoll, Michael Rycroft, Gabriela Sartori, and Hripsime Mkrtchyan.)

\section{Discussion}

As described above, Rycroft's career started with Schumann resonances, part of the "AC" atmospheric electrical system, but progressively moved towards the "DC" global circuit model. It is interesting to consider why this shift occurred, as these topics are now regarded as closely related. When Rycroft undertook his $\mathrm{PhD}$, the relationships between thunderstorm and fair weather atmospheric electricity were certainly understood in principle, since CTR Wilson had pro- 


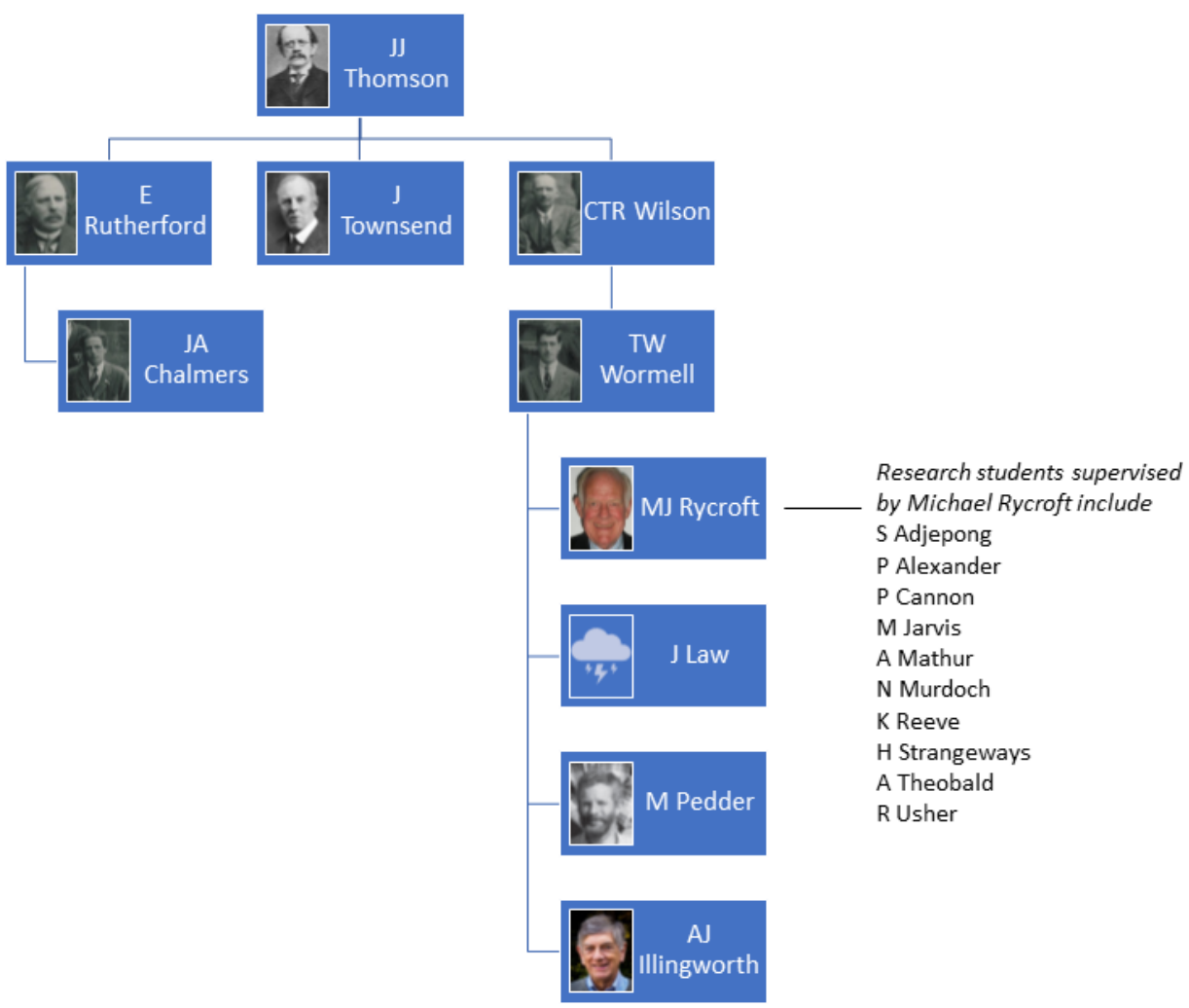

Figure 9. The Cavendish Laboratory atmospheric electricity "family tree", highlighting the contribution of Michael Rycroft. The group formed by Chalmers at Durham is described by Aplin (2018). Mike Pedder spent his career at Reading in the Department of Meteorology, subsequently joined there by Anthony Illingworth after working at University of Manchester Institute of Science and Technology (UMIST). John Law became a hospital health physicist.

vided the conceptual framework in the 1920s (Aplin et al., 2008), but there was almost no formal study of the integrated system, now known explicitly as the global circuit ${ }^{2}$. Rycroft has devoted major effort following his retirement to work on the global circuit. With hindsight, he clearly regarded this as something that he could have done earlier:

During my PhD I didn't think about the global circuit at all, as I could have done if I'd been more conscientious and not so focused on confirming the letter to Nature of Balser and Wagner. (Michael J. Rycroft, personal communication, 2018)

Given the infancy of the global circuit then as a topic, it would certainly have been a pioneering endeavour should he have chosen to work more broadly.

\footnotetext{
${ }^{2}$ The term "global circuit" itself was not in general use until around the end of the 1960s to early 1970s, (e.g. Ruhnke, 1969, and Mühleisen, 1976), with the previous terminology being much less focused, e.g. "equivalent circuit" (Israël and Lahmeyer, 1948), "electrical balance sheet" (Chalmers, 1967), "Wilson circuit" (Cobb, 1967), and the "classical picture of atmospheric electricity" (Dolezalek, 1972).
}

Rycroft's work on the global circuit reflects the opportunities available from his wide international network of collaborators, and the changing fashion in science to bring together teams of co-workers, facilitated by the emerging opportunities presented by electronic communication. The international team approach, in which the team's networking activity is funded i.e. travel, accommodation, and publishing, rather than salaries, equipment or field work, has been particularly characterised by the European Science Foundation (ESF), EU science through its COST Actions, and the International Space Science Institute in Bern. The abundance of such large collaborations reflects a major change in the practice of atmospheric science from the first phase of his work. In his own words,

During my PhD... the idea of teams of people didn't exist, woefully... (Michael J. Rycroft, personal communication, 2018)

At the beginning of Rycroft's career it was certainly true that the leading scientists mainly worked alone or with a few collaborators. In atmospheric science, collaboration and discussion, beyond the strong culture of the departmental tearoom, was very limited. For example, Rycroft never met Chalmers, who led atmospheric electricity at 
Durham, and had been a contemporary of his supervisor Wormell (Michael J. Rycroft, personal communication, 2018). Rycroft's position in the development of UK atmospheric electricity is summarised in Fig. 9, which lists his predecessors, contemporaries, and research students.

Large science teams were relatively slow to emerge in meteorology and atmospheric science, perhaps because of the enduring opportunities for small-scale experimental work provided by the ready availability of the outside world and the rapid development of computing. This meant that the subject did not require international teams to make progress in the way that particle physics and space science critically required. Eventually, collaborations between universities and the Met Office (a leading centre of research then and now) began to emerge from the 1990s onward. Technology has also helped underpin a team-working approach, with much scientific data now made routinely available via the internet. Rycroft's original scientific training was in the era of the "solitary investigator", but, despite this, as a strongwilled individual leader he may have actually contributed to the broader cultural change which has occurred through his ability to see opportunities, using teamwork and effective management, to facilitate scientific progress. Importantly, although Rycroft was trained as an experimentalist, he has also been greatly appreciative of the value of theory and modelling, and therefore of a large portion of the modern scientific world. Rycroft's ability to generate catchy acronyms, particularly useful in the days before web acronym generators, is also legendary and has usefully served to define many a team (e.g. SPECIAL) or mechanism (e.g. ALICE; Harrison et al., 2014). Over his career, his interests broadened to large-scale, indeed global, problems in geophysics. He always enjoyed making presentations at conferences organised by international bodies such as COSPAR, IUGG (International Union of Geodesy and Geophysics; particularly IAGA), URSI, the Scientific Committee on Solar-Terrestrial Physics (SCOSTEP) and SCAR, by American Geophysical Union (AGU) and EGS (now EGU), and by national bodies such as the Royal Society, the Royal Astronomical Society (RAS; especially Magnetosphere, Ionosphere and SolarTerrestrial, MIST, meetings), the Institute of Physics (Environmental Physics Group, founded by Sir Hermann Bondi, and as a member of its first organising committee), and the Institute of Mathematics and its Applications (IMA). At some time, he was a member of the COSPAR and SCOSTEP bureaus and of the RAS and IMA councils.
In summary, Rycroft's career provides a useful exemplar of one of the first to span the space age. It also demonstrates an evolution in the range of ways of working, exemplifying and perhaps contributing to the transition between the lone investigator model, as practised at the Cavendish Laboratory in the first half of the 20th century, and the modern team working scientist, who may well have moved between multiple institutions and roles across universities, the public sector, and through and between research, academia, and senior management. Above all, analysing this particular career brings out the value of supporting and encouraging colleagues with different interests to pursue their scientific endeavours for the greater good of humanity. 
Appendix A: Michael Rycroft - publications 1964-2018

1. Denisenko, Rycroft, Harrison, Mathematical simulation of the ionospheric electric field as a part of the global electric circuit, 2018, Surveys in Geophysics

2. Füllekrug, Liu, Koh, Mezentsev, Pedeboy, Soula, Enno, Sugier, Rycroft, Mapping lightning in the sky with a mini array, 2016, Geophys. Res. Lett.

3. Kudintseva, Rycroft, Nickolaenko, Odzimek, AC and DC Global Electric Circuit and the Height Profile of Atmospheric Conductivity, 2016, in: 9th international Kharkiv Symposium on Physics and Engineering of Microwaves, Millimeter and Submillimeter Waves $(M S M W)$

4. Kudintseva, Nickolaenko, Rycroft, Odzimek, AC and DC global electric circuit properties and the height profile of atmospheric conductivity, 2016, Ann. Geophys.

5. Rycroft, Thunder and lightning-what determines where and when thunderstorms occur?, 2014, Env. Res. Lett.

6. Tacza, Raulin, Macotela, Norabuena, Fernandez, Correia, Rycroft, Harrison, A new South American network to study the atmospheric electric field and its variations related to geophysical phenomena, 2014, J. Atmos. Sol.Terr. Phys.

7. Harrison, Aplin, Rycroft, Brief Communication: Earthquake-cloud coupling through the global atmospheric electric circuit, 2014, Natural hazards and earth system sciences

8. Rycroft, Nicoll, Aplin, Harrison, Recent advances in global electric circuit coupling between the space environment and the troposphere, 2012, J. Atmos. Sol.-Terr. Phys.

9. Rycroft, Harrison, Electromagnetic AtmospherePlasma Coupling: The Global Atmospheric Electric Circuit, 2012, Space Sci. Rev.

10. Rycroft, Odzimek, Effects of lightning and sprites on the ionospheric potential, and threshold effects on sprite initiation, obtained using an analog model of the global atmospheric electric circuit, 2010, J Geophys Res-Space

11. Harrison, Aplin, Rycroft, Atmospheric electricity coupling between earthquake regions and the ionosphere, 2010, J. Atmos. Sol.-Terr. Phys.

12. Gu, Rycroft, Preface to the Special Issue on "Arrays and Array Methods in Global Seismology", 2009, Surveys in Geophysics
13. Nemec, Parrot, Santolik, Rodger, Rycroft, Hayosh, Shklyar, Demekhov, Survey of magnetospheric line radiation events observed by the DEMETER spacecraft, 2009, J. Geophys. Res.-Space

14. Pasmanik, Demekhov, Trakhtengerts, Titova, Rycroft, Propagation of lower hybrid resonance waves in depleted-plasma regions in the upper auroral ionosphere, 2009, Radiophysics and quantum electronics

15. Rycroft, Odzimek, The Impact of Lightning Flashes and Sprites on the Earth's Global Electric Circuit: An Overview of Recent Modeling Results, 2009, in: Coupling of thunderstorms and lightning discharges to near-earth space

16. Aplin, Harrison, Rycroft, Investigating Earth's Atmospheric Electricity: a Role Model For Planetary Studies, 2008, Space Sci. Rev.

17. Rycroft, Harrison, Nicoll, Mareev, An Overview Of Earth's Global Electric Circuit and Atmospheric Conductivity, 2008, Space Sci. Rev.

18. Trakhtengerts, Rycroft, Whistler and Alfvén Mode Cyclotron Masers in Space, 2008, Cambridge University Press

19. Rycroft, Odzimek, Arnold, Füllekrug, Kulak, Neubert, New model simulations of the global atmospheric electric circuit driven by thunderstorms and electrified shower clouds: The roles of lightning and sprites, 2007, J. Atmos. Sol.-Terr. Phys.

20. Titova, Demekhov, Pasmanik, Trakhtengerts, Manninen, Turunen, Rycroft, Ground-based observations at $L$ $\sim 6$ of multi-band structures in VLF hiss, 2007, Geophys. Res. Lett.

21. Trakhtengerts, Demekhov, Titova, Kozelov, Santolik, Macusova, Gurnett, Pickett, Rycroft, Nunn, Formation of VLF chorus frequency spectrum: Cluster data and comparison with the backward wave oscillator model, 2007, Geophys. Res. Lett.

22. Demekhov, Trakhtengerts, Rycroft, Nunn, Electron acceleration in the magnetosphere by whistler-mode waves of varying frequency, 2006, Geomagn. \& Aeron.

23. Palmer, Rycroft, Cermack, Solar and geomagnetic activity, extremely low frequency magnetic and electric fields and human health at the Earth's surface, 2006, Surveys in Geophysics

24. Rycroft, Space exploration goals for the 21st century, 2006, Space Policy

25. Crosby, Rycroft, Tulunay, Overview of a graduate course delivered in Turkey, emphasizing solar-terrestrial physics and space weather, 2006, Surveys in Geophysics 
26. Rycroft, Electrical processes coupling the atmosphere and ionosphere: An overview, 2006, J. Atmos. Sol.-Terr. Phys.

27. Kartalev, Rycroft, Füllekrug, Papitashvili, Keremidarska, A possible explanation for the dominant effect of South American thunderstorms on the Carnegie curve, 2006, J. Atmos. Sol.-Terr. Phys.

28. Füllekrug, Rycroft, The contribution of sprites to the global atmospheric electric circuit, 2006, Earth Planets and Space

29. Rycroft, Introduction to the Physics Of Sprites, Elves and Intense Lightning Discharges, 2006, in: Sprites, elves and intense lightning discharges

30. Rycroft, Kartalev, Papitashvili, Keremidarska, On the effect of near-equatorial thunderstorms on the global distribution of ionospheric potential, 2005, in: Greenhouse gases, ozone, and electrodynamics; their changes in the middle atmosphere and lower thermosphere

31. Craven, Rycroft, Analysis of Secondary Electron Emission Spectra of equal-LET Protons And Alpha Particles for Purposes of Radiation Quality and Spaceflight Hazard Assessment, 2005, in: Space life sciences: groundbased iron-ion biology and physics, including shielding

32. Rycroft, Füllekrug, The initiation and evolution of SPECIAL, 2004, J. Atmos. Sol.-Terr. Phys.

33. Kartalev, Rycroft, Papitashvili, A quantitative model of the effect of global thunderstorms on the global distribution of ionospheric electrostatic potential, 2004, J. Atmos. Sol.-Terr. Phys.

34. Trakhtengerts, Rycroft, Nunn, Demekhov, Cyclotron acceleration of radiation belt electrons by whistlers, 2003, J. Geophys. Res.-Space

35. Nunn, Demekhov, Trakhtengerts, Rycroft, VLF emission triggering by a highly anisotropic energetic electron plasma, 2003, Ann. Geophys.

36. Pasmanik, Demekhov, Nunn, Trakhtengerts, Rycroft, Cyclotron amplification of whistler-mode waves: A parametric study relevant to discrete VLF emissions in the Earth's magnetosphere, 2002, J. Geophys. Res.Space

37. Rycroft, Füllekrug, Crosby, Rodger, The ESF Scientific Network SPECIAL, 2002, Solspa 2001: Proc 2nd solar cycle and space weather Euroconference

38. Trakhtengerts, Demekhov, Pasmanik, Titova, Kozelov, Nunn, Rycroft, Highly anisotropic distributions of energetic electrons and triggered VLF emissions, 2001, Geophys. Res. Lett.
39. Cho, Rycroft, Non-uniform ionisation of the upper atmosphere due to the electromagnetic pulse from a horizontal lightning discharge, 2001, J. Atmos. Sol.-Terr. Phys.

40. Rodger, Cho, Clilverd, Rycroft, Lower ionospheric modification by lightning-EMP: Simulation of the night ionosphere over the United States, 2001, Geophys. Res. Lett.

41. Crosby, Rycroft, "ESF network on space weather and the Earth's weather, SPECIAL", 2001, Physics and chemistry of the earth part $C$ - solar-terrestrial and planetary science

42. Rycroft, Untitled, 2001, Surveys in Geophysics

43. Rycroft, Füllekrug, Crosby, Rodger, "The ESF Scientific Network, SPECIAL", 2001, Workshop on IonAerosol-Cloud Interactions

44. Rycroft, Golden jubilee issue - Preface, 2000, J. Atmos. Sol.-Terr. Phys.

45. Rycroft, Israelsson, Price, The global atmospheric electric circuit, solar activity and climate change, 2000, $J$. Atmos. Sol.-Terr. Phys.

46. Trakhtengerts, Rycroft, Whistler-electron interactions in the magnetosphere: new results and novel approaches, 2000, J. Atmos. Sol.-Terr. Phys.

47. Crosby, Rycroft, SPECIAL: An interdisciplinary ESF Network on Space Weather and the Earth's Weather, 2000, Proceedings of the 1st solar and space weather euroconference on the solar cycle and terrestrial climate

48. Rycroft, Special issue - Space techniques for environmental risks - Preface, 2000, Surveys in Geophysics

49. Rycroft, From Environmental Risks, As Problems, To Earth Observations As Solutions To Those Problems, 2000, Surveys in Geophysics

50. Rycroft, Untitled, 1999, J. Atmos. Sol.-Terr. Phys.

51. Cho, Rycroft, Computer simulation of the electric field structure and optical emission from cloud-top to the ionosphere, 1998, J. Atmos. Sol.-Terr. Phys.

52. Rycroft, Cho, Modelling electric and magnetic fields due to thunderclouds and lightning from cloud-tops to the ionosphere, 1998, J. Atmos. Sol.-Terr. Phys.

53. Pasmanik, Trakhtengerts, Demekhov, Lyubchich, Titova, Yahnina, Rycroft, Manninen, Turunen, A quantitative model for cyclotron wave-particle interactions at the plasmapause, 1998, Ann Geophys-atmospheres hydrospheres and space sciences 
54. Trakhtengerts, Rycroft, Sounding the magnetosphere by signals from VLF radio transmitters, 1998, J. Atmos. Sol.-Terr. Phys.

55. Trakhtengerts, Demekhov, Polyakov, Manninen, Turunen, Rycroft, ELF/VLF radio signals caused by ionospheric demodulation of $\mathrm{MF} / \mathrm{HF}$ radio transmitter signals, 1997, J. Atmos. Sol.-Terr. Phys.

56. Trakhtengerts, Rycroft, A new parametric reflection mechanism for ducted whistlers and an explanation of precursors, 1997, J. Atmos. Sol.-Terr. Phys.

57. Cho, Rycroft, The decomposition of CFCs in the troposphere by lightning, 1997, J. Atmos. Sol.-Terr. Phys.

58. Rycroft, Space science education - An interdisciplinary and international programme, 1997, Problems of space science education and the role of teachers

59. Lee, LeDilosquer, Singh, Hobbs, Giannakopoulos, Plantevin, Law, Pyle, Rycroft, Implications of NOy emissions from subsonic aircraft at cruise altitude, 1997, Proc. Institut Mech. Eng. G-J. Aerospace Eng.

60. Lee, LeDilosquer, Singh, Rycroft, Further considerations of engine emissions from subsonic aircraft at cruise altitude, 1996, Atmospheric Environment

61. Rycroft, Professor Sir Granville Beynon (1914-1996): A great man and a good man - Obituary, 1996, J. Atmos. Terr. Phys.

62. Sukhorukov, Mishin, Stubbe, Rycroft, On blue jet dynamics, 1996, Geophys. Res. Lett.

63. Trakhtengerts, Rycroft, Demekhov, Interrelation of noise-like and discrete ELF/VLF emissions generated by cyclotron interactions, 1996, J. Geophys. Res.-Space

64. Craven, Rycroft, An Assessment of Galactic CosmicRadiation Quality Considering Heavy-Ion Track Structures Within the Cellular Environment, 1996, "Physical, chemical, biochemical and biological techniques and processes"

65. Sazhin, Rycroft, Ken Bullough: a scientist and a friend, 1995, J. Atmos. Terr. Phys.

66. Rycroft, Appleton, Edward centenary issue - preface, 1994, J. Atmos. Terr. Phys.

67. Rycroft, Beynon, Granville - A celebration of his 80th birthday on 24 may 1994 - Preface, 1994, J. Atmos. Terr. Phys.

68. Willis, Hewish, Rishbeth, Rycroft, Synoptic data for solar-terrestrial physics - the U.K. contribution to longterm monitoring, 1994, J. Atmos. Terr. Phys.
69. Rycroft, Electrodynamics of the middle atmosphere preface, 1994, J. Atmos. Terr. Phys.

70. Rycroft, Some effects in the middle atmosphere due to lightning, 1994, J. Atmos. Terr. Phys.

71. Kulkarni, Rycroft, On the effect of a beam of energetic electrons on the whistler-mode growth rate due to gyroresonant interactions, 1992, J. Atmos. Terr. Phys.

72. Kulkarni, Rycroft, The suppressing effect of fieldaligned currents on VLF emissions in the magnetosphere, 1992, J. Atmos. Terr. Phys.

73. Rycroft, Solar-terrestrial physics - Preface, 1991, J. Atmos. Terr. Phys.

74. Rycroft, Interactions between whistler-mode waves and energetic electrons in the coupled system formed by the magnetosphere, ionosphere and atmosphere, 1991, J. Atmos. Terr. Phys.

75. Omura, Nunn, Matsumoto, Rycroft, A review of observational, theoretical and numerical-studies of VLF triggered emissions, 1991, J. Atmos. Terr. Phys.

76. Rycroft, Long-Term Solar-Terrestrial Data Sets and Their Value, 1991, J. Geomag. \& Geoelect.

77. Farmer, Jones, Williams, Moffett, Samson, Rycroft, Lester, Mccrea, The ionosphere south of EISCAT: measurements by the UK-South programme, 1990, J. Atmos. Terr. Phys.

78. Rycroft, The Antarctic Atmosphere: A Hot Topic in a Cold Cauldron, 1990, Geographical Journal

79. Rycroft, Quo vadimus re the springtime Antarctic ozone depletion?, 1990, Advances in Space Research

80. Rycroft, Solar Terrestrial Physics - An Overview, 1989, Phil. Trans. Roy. Soc. Lond. A

81. Tarcsai, Strangeways, Rycroft, Error sources and travel time residuals in plasmaspheric whistler interpretation, 1989, J. Atmos. Terr. Phys.

82. Rycroft, The springtime Antarctic ozone depletion, 1988, Quart. J. Roy. Astron. Soc.

83. Mackie, Rycroft, Health and the ozone layer, 1988, British Medical Journal

84. Kulkarni, Rycroft, Effect of magnetic field-aligned currents on VLF emissions in the magnetosphere, 1988, Indian Journal of Radio \& Space Physics

85. Rycroft, Some aspects of geomagnetically conjugate phenomena, 1987, Ann. Geophys. A-upper atmosphere and space sciences 
86. Rycroft, Strange new whistlers, 1987, Nature

87. Rycroft, Atmospheric Studies by Optical Methods preface, 1987, Surveys in Geophysics

88. Rycroft, Antarctica - A unique laboratory for atmospheric studies by optical methods, 1987, Surveys in Geophysics

89. Rycroft, Magnetospheric forcing of upper atmosphere dynamics, 1987, Nature

90. Rycroft, Plasma - the fourth state of matter?, 1986, $\mathrm{Na}$ ture

91. Penkett, Jones, Rycroft, Simmons, An interhemispheric comparison of the concentrations of bromine compounds in the atmosphere, 1985, Nature

92. Rycroft, Ionospheric physics: How to make a long antenna, 1985, Nature

93. Rycroft, Atmospheric physics: Interaction between whistlers and radiation belt electrons, 1984, Nature

94. Rycroft, Smith, Jones, Dudeney, Shawhan, Solar terrestrial physics: Global geospace study, 1984, Nature

95. Jones, Rycroft, The plasma physics of the Active Magnetospheric Particle Tracer Explorers (AMPTE) mission, 1984, Plasma physics and controlled fusion

96. Strangeways, Madden, Rycroft, High latitude observations of whistlers using three spaced goniometer receivers, 1983, J. Atmos. Terr. Phys.

97. Kintner, Brittain, Kelley, Carpenter, Rycroft, In situ measurements of transionospheric VLF wave injection, 1983, J. Geophys. Res.-Space

98. Rycroft, Space-shuttle: Spacecraft that glows in the night, 1983, Nature

99. Small, Rycroft, The Q-value and resistance of the heliospheric resonator model for the 22-year solar-cycle, 1983, Planetary and Space Sci.

100. Cannon, Rycroft, Schumann resonance frequency variations during sudden ionospheric disturbances, 1982, $J$. Atmos. Terr. Phys.

101. Strangeways, Rycroft, Jarvis, Multi-station VLF direction-finding measurements in eastern Canada, 1982, J. Atmos. Terr. Phys.

102. Cannon, Turunen, Rycroft, Ionospheric ELF radio signal generation due to $\mathrm{LF}$ and/or MF radio transmissions-II. Interpretation, 1982, J. Atmos. Terr. Phys.
103. Rycroft, Ionospheric hole caused by rocket engine, 1982, Nature

104. Rycroft, Analysing atmospheric carbon dioxide levels, 1982, Nature

105. Denby, Bullough, Alexander, Rycroft, Observational and theoretical studies of a cross meridian refraction of VLF waves in the ionosphere and magnetosphere, 1980, J. Atmos. Terr. Phys.

106. Strangeways, Rycroft, Trapping of whistler-waves through the side of ducts, 1980, J. Atmos. Terr. Phys.

107. Strangeways, Rycroft, Systematic errors in VLF direction-finding of whistler ducts -II, 1980, J. Atmos. Terr. Phys.

108. Bering, Rosenberg, Benbrook, Detrick, Matthews, Rycroft, Saunders, Sheldon, Electric fields, electron precipitation, and VLF radiation during a simultaneous magnetospheric substorm and atmospheric thunderstorm, 1980, J. Geophys. Res.-Space

109. Rycroft, Active experiments in space plasmas, 1980, Nature

110. Turunen, Cannon, Rycroft, ELF radio signals in the auroral ionosphere generated by non-linear demodulation of LF and/or MF transmissions, 1980, Nature

111. Cannon, Rycroft, Gibbons, Woolliscroft, Observations of whistlers at high-latitudes in northern Scandinavia and on the GEOS-II spacecraft, 1979, Geophys. J. Roy. Astron. Soc.

112. Kulkarni, Murdoch, Rycroft, Amplification of whistler mode radiation in the magnetosphere and the triggering of artificially stimulated emissions (ASE), 1979, Geophys. J. Roy. Astron. Soc.

113. Murdoch, Kulkarni, Rycroft, Generation of rising frequency ELF/VLF radio emissions, 1979, Geophys. J. Roy. Astron. Soc.

114. Kulkarni, Rycroft, The effect of plasma drift on the electromagnetic cyclotron instability, 1979, Phys. Lett. A

115. Lemaire, Rycroft, Roth, Control of impulsive penetration of solar wind irregularities into the magnetosphere by the interplanetary magnetic field direction, 1979, Planet \& Space Sci.

116. Madden, Rycroft, Smith, Ground-based ELF/VLF observations at high latitudes during passes of GEOS-1 and ISEE-1 and -2, 1978, Space Sci. Rev.

117. Rycroft, The plasmapause revisited, 1977, Nature 
118. Rycroft, Williams, Theobald, Calculations of a physical mechanism which may be important in relating active regions on sun and interplanetary magnetic-field sector structure to observed changes of vorticity in winter northern hemisphere, 1977, Trans AGU

119. Theobald, Rycroft, Williams, Calculation of effects of variations of solar cosmic rays and UV radiation on middle atmosphere, 1977, Trans $A G U$

120. Adjepong, Rycroft, Dalziel, Pratt, Thomas, Coherency between precipitated and trapped energetic electrons at high latitudes, 1976, J. Atmos. Terr. Phys.

121. Rycroft, Gyroresonance interactions in outer plasmasphere, 1976, J. Atmos. Terr. Phys.

122. Reeve, Rycroft, A mechanism for precursors to whistlers, 1976, J. Geophys. Res.-Space

123. Everhard-Barker, Rycroft, Heard, Smith, ELF and VLF radio emissions following a barium shaped charge release at L roughly 6.5, in: Space research XVI, 1976, Proceedings of the Open Meetings of Working Groups on Physical Sciences, and Symposium and Workshop on Results from Coordinated Upper Atmosphere Measurement Programs, Varna, Bulgaria

124. Reeve, Rycroft, Unducted VLF energy from tropical lightning as a possible source of mid-latitude VLF emissions and electron precipitation, 1976, J. Geophys. Res.Space

125. Rycroft, Review of in situ observations of plasmapause, 1975, Annales de Geophysique

126. Rycroft, Mathur, Ojastu, Cyclotron resonance amplification of whistler triggered emissions just inside plasmapause, 1975, Annales de Geophysique

127. Rycroft, Review of in situ observations of plasmapause, 1975, Trans. AGU

128. Rycroft, Generation and amplification of VLF waves via cyclotron resonance just inside plasmapause, 1975, Trans. $A G U$

129. Rycroft, Geomagnetic-field models and analysis of whistlers, 1975, Trans. AGU

130. Rycroft, Some calculations on equatorial gyroresonance interactions on Siple-Roberval field line, 1975, Trans. $A G U$

131. Everhard-Barker, Rycroft, Heard, Smith, Bottoms, Pongrantz, VLF radio phenomena following a barium shaped charge release at $L$ approximately equals 6.5 , 1975, Trans. $A G U$
132. Rycroft, Magnetospheric plasma flow and electric fields derived from whistler observations, 1974, Quart. J. Roy. Astron. Soc.

133. Rycroft, Mathur, Determination of minimum group delay of a non-nose whistler, 1973, J. Atmos. Terr. Phys.

134. Rycroft, Enhanced energetic electron intensities at $100 \mathrm{~km}$ altitude and a whistler propagating through the plasmasphere, 1973, Planet \& Space Sci.

135. Rycroft, Cyclotron interactions between particles and waves in magnetosphere, 1973, Quart. J. Roy. Astron. Soc.

136. Reeve, Rycroft, The eclipsed lower ionosphere as investigated by natural very low frequency radio signals, 1972, J. Atmos. Terr. Phys.

137. Mathur, Rycroft, Electron-density profiles deduced from plasmapause whistlers observed in United Kingdom, 1972, J. Geophys. Res.

138. Mathur, Sagredo, Rycroft, Ring Current Effect On Magnetospheric Electron Density Profiles derived from Plasmapause Whistlers, 1972, Nature

139. Rycroft, VLF Emissions in the Magnetosphere, 1972, Radio Sci.

140. Rycroft, Burnell, Statistical analysis of movements of ionospheric trough and plasmapause, 1970, J. Geophys. Res.

141. Rycroft, Reeve, VLF Radio Signals observed in Newfoundland during the Solar Eclipse of March 7, 1970, 1970, Nature

142. Thomas, Rycroft, Exospheric plasma during international years of quiet sun, 1970, Planet \& Space Sci.

143. Rycroft, Thomas, The magnetospheric plasmapause and the electron density trough at the Alouette I orbit, 1970, Planet \& Space Sci.

144. Rycroft, A review of satellite observations of VLF phenomena in the magnetosphere, 1967, Proc. IEE Conf on $M F, L F$, and VLF Radio Propagation

145. Rycroft, Wormell, Chapter 29 - The Natural ELF. Electromagnetic Noise in the Band 2-40 C/S; Apparatus and Some Preliminary Results, 1964, AGARDograph

146. Knox, Rycroft, Observations of Background Electromagnetic Noise in East Greenland, 1964, Nature

147. Rycroft, Resonances of the Earth-ionosphere cavity observed at Cambridge, England, 1964, Radio Science

148. Rycroft, Low frequency disturbances of natural origin of the electric and magnetic field of the earth, 1964, PhD Thesis, Cavendish Laboratory, Cambridge 
Data availability. The data presented in Figs. 4 and 5 can be obtained by searching the Web of Science database and by analysing Rycroft's list of publications, provided in the Appendix.

Author contributions. KLA led and managed the preparation of the paper, to which all authors contributed text and comments.

Competing interests. The authors declare that they have no conflict of interest.

Acknowledgements. This paper was inspired by a tribute meeting held in Bath on 16 November 2018, which was attended by Michael's wife Mary and one of his sons, Matthew, as well as many colleagues. We acknowledge the contributions of Michael's family, Richard Horne, Clive Rodgers, and Mark Saunders. Last but not least, we thank Michael Rycroft himself for checking our paper for factual accuracy. We also thank Norma Crosby for her review and Kristian Schlegel for editing the paper.

Review statement. This paper was edited by Kristian Schlegel and reviewed by Norma B. Crosby.

\section{References}

Aplin, K. L.: Atmospheric electricity at Durham: the scientific contributions and legacy of J. A. ("Skip") Chalmers (1904-1967), Hist. Geo Space. Sci., 9, 25-35, https://doi.org/10.5194/hgss-925-2018, 2018.

Aplin, K. L., Harrison, R. G., and Rycroft, M. J.: Investigating Earth's atmospheric electricity: a role model for planetary studies, Space Sci. Rev., 137, 11-27, https://doi.org/10.1007/s11214008-9372-x, 2008.

Balser, M. and Wagner, C. A.: Observations of Earth-ionosphere cavity resonances, Nature, 188, 638-641, 1960.

Benoit, R. and Houri, A.: Propagation of very low frequencies in the earth- ionosphere system, Ann. Geophys., 17, 370-373, 1961.

Blackband, W. T.: Propagation of radio waves at frequencies below $300 \mathrm{kc} / \mathrm{s}$, Proceedings of the 7 th meeting of the AGARD ionospheric research committee, Munich, 4, 3-478, available at: https://www.sciencedirect.com/bookseries/agardograph/ vol/74/suppl/C (last access: 28 May 2020), 1964.

Chalmers, J. A.: Atmospheric Electricity, 2nd Edn., Pergamon Press, Oxford, UK, 1967.

Cobb, W. E.: Evidence of a solar influence on the atmospheric electric elements at Mauna Loa Observatory, Mon. Weather Rev., 95, 905-911, 1967.

Dee, P.: Interview with Charles Weiner, transcript at AIP Oral Histories, available at: https://www.aip.org/history-programs/ niels-bohr-library/oral-histories (last access: 28 May 2020), 1971.

Dee, P. and Wormell, T. W.: An Index to C. T. R. Wilson's laboratory records and notebooks in the Library of the Royal Society, Notes Rec. Roy. Soc., 18, 54-66, https://doi.org/10.1098/rsnr.1963.0008, 1963.
Dolezalek, H.: Discussion of the fundamental problem of atmospheric electricity, Pure Appl. Geophys., 100, 8-43, 1972.

Farman, J., Gardiner, B., and Shanklin, J.: Large losses of total ozone in Antarctica reveal seasonal $\mathrm{ClO}_{x} / \mathrm{NO}_{x}$ interaction, Nature, 315, 207-210, https://doi.org/10.1038/315207a0, 1985.

Farman, J.: Interview with Paul Merchant, An Oral History of British Science, available at: https://sounds.bl.uk/ Oral-history/Science/021M-C1379X0007XX-0015V0 (last access: 28 May 2020), 2010.

Fournier, H.: Some aspects of the first high-frequency geomagnetic recordings obtained at Garchy, C.R. Acad. Sci. (France), 251, 962-964, 1960.

Harrison, R. G.: Climate change and the global atmospheric electrical system, Atmos. Environ., 31, 3483-3484, 1997.

Harrison, R. G.: The cloud chamber and CTR Wilson's legacy to atmospheric science, Weather, 66, 276-279, 2011.

Harrison, R. G., Aplin, K. L., and Rycroft, M. J.: Brief Communication: Earthquake-cloud coupling through the global atmospheric electric circuit, Nat. Hazards Earth Syst. Sci., 14, 773777, https://doi.org/10.5194/nhess-14-773-2014, 2014.

Israël, H. and Lahmeyer, G.: Studien über das atmosphärische Potentialgefälle: 1 - Das Auswahlprinzip der luftelektrisch "ungestörten Tage", Terrestrial Magnetism and Atmospheric Electricity, 53, 373-386, 1948.

Jones, D. L.: Observations on extremely low frequency (E.L.F.) electromagnetic noise of terrestrial origin, $\mathrm{PhD}$ thesis, King's College London, 1963.

Lokken, J. E., Shand, J. A., Wright, C. S., Martin, L. H., Brice, N. M., and Helliwell, R. A.: Stanford-Pacific Naval Laboratory conjugate point experiment, Nature, 192, 319-320, 1961.

Longair, M.: Maxwell's Enduring Legacy: A scientific history of the Cavendish Laboratory, Cambridge University Press, Cambridge, UK, 2016.

Macky, W. A.: An attempt to detect radiation in thunderclouds, Proc. Camb. Philos. S.-M., 34, 70-73, 1933.

Mühleisen, R.: The global circuit and its parameters, in: Electrical processes in atmospheres, 467-476, Steinkopff, Darmstadt, Germany, 1976.

Polk, C. and Fitchen, F.: Schumann resonances of the Earth ionosphere cavity - Extremely low frequency reception at Kingston, RI, J. Res. NBS D Rad. Sci., 66, 313-318, 1962.

Powell, C. F.: Fragments of autobiography, in: Histories of Physics in Bristol, edited by: Chambers, R. G. and Hart, M., undated (reproduced in 1987).

Price, C.: Global surface temperatures and the atmospheric electrical circuit, Geophys. Res. Lett., 20, 1363-1366, 1993.

Reeve, C. D. and Rycroft, M. J.: Expedition to Iceland, 1969, Phys. Bull., 22, 145-147, 1971.

Reeve, C. D. and Rycroft, M. J.: The eclipsed lower ionosphere as investigated by natural very low frequency radio signals, J. Atmos. Terr. Phys., 34, 667-672, 1972.

Ruhnke, L.: Area averaging of atmospheric electric currents, J. Geomagn. Geolectr., 21, 453-462, 1969.

Rycroft, M. J.: Low frequency disturbances of natural origin of the electric and magnetic field of the earth, $\mathrm{PhD}$ Thesis, University of Cambridge, 1964.

Rycroft, M. J.: Enhanced energetic electron intensities at $100 \mathrm{~km}$ altitude and a whistler propagating through the plasmasphere, Planet. Space Sci., 21, 239-251, 1973. 
Rycroft, M. J.: The plasmapause revisited, Nature, 267, 671-672, https://doi.org/10.1038/267671b0, 1977.

Rycroft, M. J.: Analysing atmospheric carbon dioxide levels, Nature, 295, 190-191, https://doi.org/10.1038/295190a0, 1982.

Rycroft, M. J.: The Universe, the quarterly report of International Space University, 7, p. 13, 1995.

Rycroft, M. J.: A personal voyage among space physics disciplines, J. Geophys. Res., in preparation, 2020.

Rycroft, M. J. and Füllekrug, M.: The initiation and evolution of SPECIAL, J. Atmos. Sol.-Terr. Phy., 66, 1103-1113, 2004.

Rycroft, M. J. and Wormell, T. W.: The Natural E.L.F. Electromagnetic Noise in the Band 2-40 C/S, Apparatus and Some Preliminary Results, AGARDograph, 74, 421-434, https://doi.org/10.1016/B978-0-08-010268-9.50033-0, 1964.

Rycroft, M. J., Israelsson, S., and Price, C.: The global atmospheric electric circuit, solar activity and climate change, J. Atmos. Sol.Terr. Phy., 62, 1563-1576, 2000.

Schumann, W. O.: Über die strahlungslosen Eigenschwingungen einer leitendenden Kugel die von einer Luftschicht umgeben ist, Zeitschrift Für Naturforschung, 7a, 149-154 \& 250-252, 1952.
Schumann, W. O. and König, H.: Über die Beobachtung von "atmospherics" bei geringster Frequenz, Naturwissenschaften, 41, 183-184, 1954.

Swinnerton-Dyer, H. P. F.: The calculation of power spectra, Comput. J., 5, 16-23, 1963.

Turunen, T., Cannon, P. S., and Rycroft, M. J.: ELF radio signals in the auroral ionosphere generated by non-linear demodulation of LF and/or MF transmissions, Nature, 286, 375-377, 1980.

Williams, E. R.: The Schumann resonance: a global thermometer, Science, 256, 1184-1187, 1992.

Wilson, C. T. R.: On some determinations of the sign and magnitude of electric discharges in lightning flashes, P. Roy. Soc. A, 92, 555-574, 1916.

Wormell, T. W.: Observations on electrical phenomena produced by thunderstorms and showers, $\mathrm{PhD}$ Thesis, University of Cambridge, 1929. 